\title{
REGULAÇÃO DE VELOCIDADE EM MOTORES DE CORRENTE CONTÍNUA
}

\section{Introdução}

Uma grande parte das aplicações em que se utiliza força motriz beneficiaria, em termos de consumo de energia elétrica e de desempenho global, se a velocidade do motor se ajustasse às necessidades do processo. Existem muitas aplicações em que é necessário regulação e controlo de velocidade, como em máquinas ferramentas, ventoinhas, elevadores, veículos de tração elétrica, entre outras.

A utilização de variadores eletrónicos de velocidade (VEVs) permite responder a alterações nas condições de carga do motor através da variação da sua velocidade. Através da regulação da velocidade de rotação dos motores, os variadores eletrónicos de velocidade proporcionam uma melhoria das condições de funcionamento dos processos, um menor desgaste dos componentes mecânicos, um menor ruído de funcionamento e, fundamentalmente, uma substancial poupança de eletricidade.

Os motores de corrente contínua (DC) são ainda muito utilizados em sistemas que requerem variação de velocidade. Nestes motores, o controlo e a regulação de velocidade acima e abaixo da respetiva velocidade nominal é facilmente conseguido, sendo os reguladores de velocidade destas máquinas mais simples e menos dispendiosos que os reguladores de velocidade usados nas máquinas de corrente alternada (AC).

As tecnologias inerentes ao controlo e regulação de velocidade evoluiu muito nos últimos anos.

No sistema clássico pelo método Ward-Leonard, máquinas rotativas eram utilizadas para variar a velocidade dos motores DC. Atualmente, são utilizados conversores eletrónicos com semicondutores de estado sólido para esta finalidade.

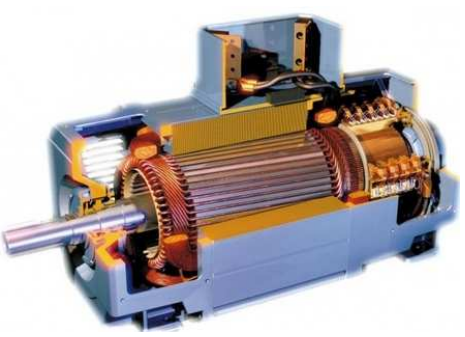

Figura 1. Motor de Corrente Contínua

\section{Sistema Ward-Leonard}

Este sistema apareceu por volta de 1890 e utiliza um grupo motor-gerador (M-G) para controlar a velocidade do motor DC, como se apresenta na Figura 2. O motor do grupo M-G (normalmente um motor AC de indução) gira a velocidade constante. Variando $\mathbf{R C}_{1}$ (reóstato de excitação do gerador) é possível variar a corrente de excitação do gerador ig, alterando assim a tensão $\mathbf{V}$ quer aos terminais do gerador quer aos terminais do motor. A variação da tensão $\mathbf{V}$ aos terminais do motor DC permite variar a velocidade deste. Este sistema funciona em dois modos de controlo.
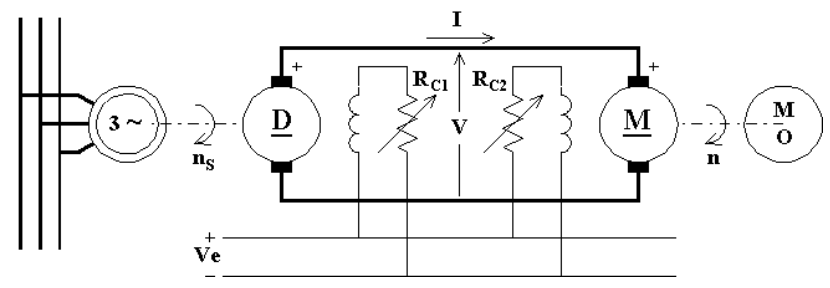

Figura 2. Sistema Ward-Leonard

\section{a) Controlo pela Tensão na Amadura V}

Neste modo de controlo a corrente excitação do motor através de $\mathbf{R C}_{\mathbf{2}}$ (reóstato de excitação do motor) é mantida constante e no seu valor nominal. A corrente de excitação do gerador é ajustada em $\mathbf{R C}_{1}$, para variar a tensão desde zero até ao seu valor nominal. A velocidade do motor irá variar desde zero até à velocidade nominal, como se pode ver na figura 3. 


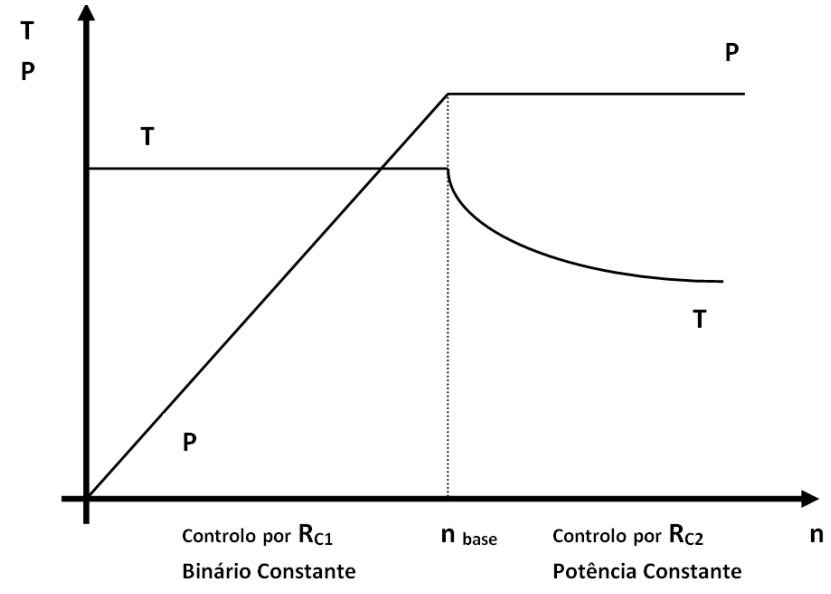

Figura 3. Sistema Ward-Leonard. Regulação mista

b) Controlo pela corrente de excitação

Este modo de controlo é utilizado para variar a velocidade acima do valor nominal. Neste caso, a tensão na armadura mantém-se constante e vai-se diminuindo a corrente de excitação do motor em RC2, obtendo-se assim velocidades mais elevadas. Como a corrente na armadura vai-se manter aproximadamente constante, diz-se que o motor funciona a potência constante. Obviamente que o binário do motor decresce ligeiramente com o aumento da velocidade, como se pode ver na Figura 3.

\section{Controlo Eletrónico}

Os conversores de estado sólido são atualmente usados para substituir o grupo D-M do sistema Ward-Leonard no controlo de velocidade dos motores DC. A Figura 4 apresenta o diagrama de blocos de um sistema conversor de estado sólido. Os conversores utilizados baseiam-se em retificadores e choppers de comutação controlada.

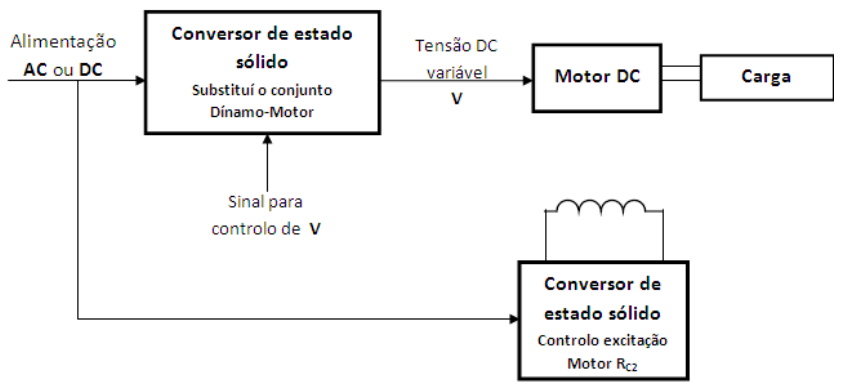

Figura 4. Diagrama de blocos de um sistema conversor de estado sólido

\subsection{Retificadores controlados}

Quando a fonte de alimentação é alternada, os retificadores podem ser utilizados para converter uma tensão constante AC numa fonte de tensão variável DC. Se os dispositivos de comutação forem todos dispositivos controlados, como os tirístores, o conversor é denominado de Totalmente Comandado. Se os dispositivos comutadores forem metade deles tirístores e a outra metade díodos, o conversor é denominado de Semicomandado. Como é apresentado na Figura 5, o ângulo $\boldsymbol{\alpha}$ de disparo dos tirístores determina o valor médio da tensão de saída Vt. O sinal de controlo Vc varia o ângulo de disparo $\boldsymbol{\alpha}$ e, consequentemente, varia a tensão Vt.

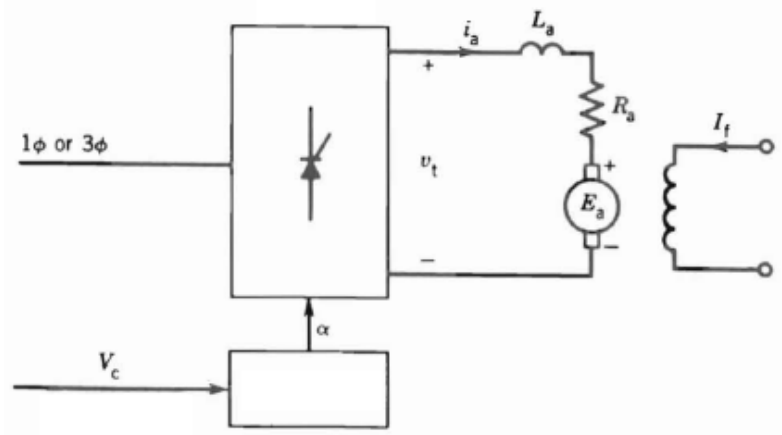

Figura 5. Retificador controlado para controlo velocidade de motores DC

Alimentação monofásica: conversor totalmente controlado

$$
V_{\mathrm{t}}=\frac{2 \sqrt{2} V_{p}}{\pi} \cos \alpha
$$

Alimentação monofásica: conversor semicontrolado

$$
V_{\tau}=\frac{\sqrt{2} V_{p}}{\pi}(1+\cos \alpha)
$$

Alimentação trifásica: conversor totalmente controlado

$$
V_{t}=\frac{3 \sqrt{ } 6 V_{p}}{\pi} \cos \alpha
$$

Alimentação trifásica: conversor semicontrolado

$$
V_{t}=\frac{3 \sqrt{6} V_{p}}{2 \pi}(1+\cos \alpha)
$$

Onde $\mathbf{V p}$ é o valor eficaz da tensão alternada monofásica. A variação da tensão Vt aos terminais do motor em função do ângulo de disparo $\alpha$ é apresentada na Figura 6, para ambos 
os conversores, totalmente controlado e semicontrolado. Se a queda de tensão $\mathbf{R}_{\mathrm{a}} \mathbf{I}_{\mathbf{a}}$ for desprezada ( $\left.\mathbf{V} \mathbf{t}=\mathbf{E a}\right)$, as curvas da Figura 6 também representam a variação de Ea e, como tal, a variação da velocidade com o ângulo de disparo.

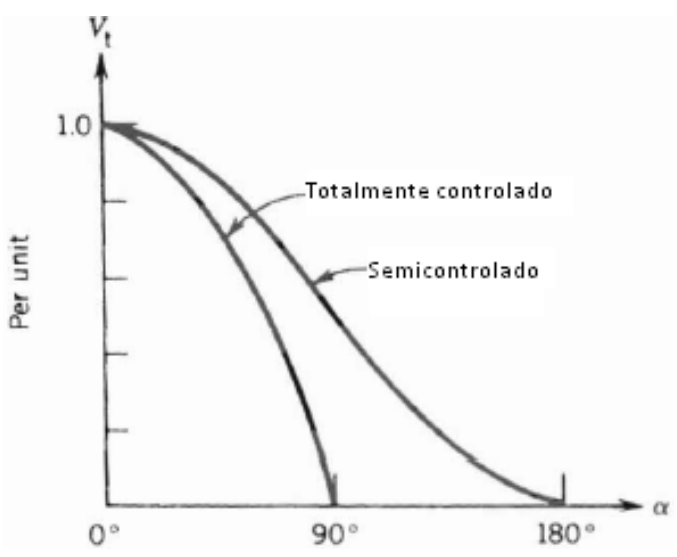

Figura 6. Caraterísticas do retificador controlado

\subsection{Choppers}

O chopper converte uma tensão contínua fixa numa tensão contínua variável. O diagrama esquemático e as formas de onda são apresentadas na Figura 7.

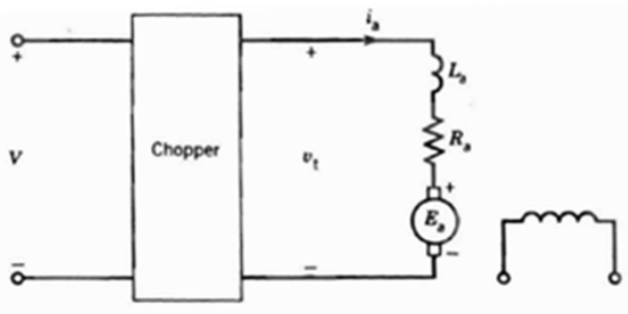

(a)

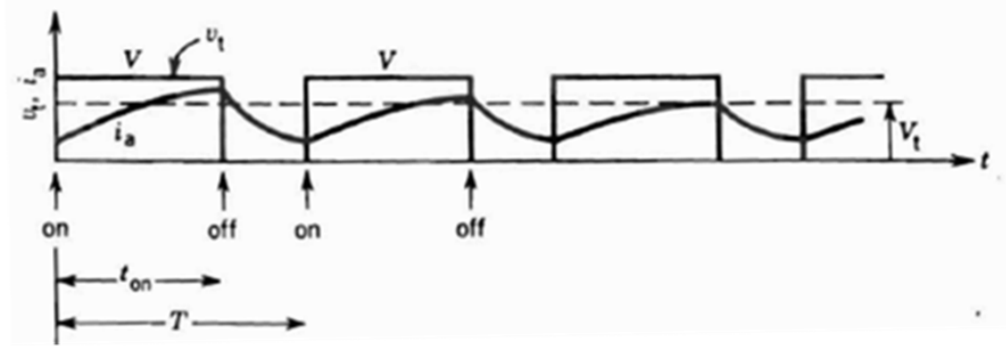

Figura 7. Circuito e Operação de um Chopper

$$
\mathrm{V}_{\mathrm{t}}=\frac{\mathrm{t}_{\mathrm{on}}}{\mathrm{T}} \times \mathrm{V}=\alpha \mathrm{V}
$$

Em que: Ton representa interruptor fechado, $\boldsymbol{\alpha}$ o índice de modulação do chopper e T o período de comutação.

\subsection{Operação em malha fechada}

Em acionamentos do motor DC onde se exige uma velocidade rigorosamente constante, o controlo em malha aberta não é totalmente satisfatório.

Em malha aberta, variações no binário da carga originam variações na velocidade. Em controlo em malha fechada a velocidade pode ser mantida constante, ajustando a tensão aos terminais do motor de acordo com as variações do binário de carga. A Figura 8 apresenta um diagrama de blocos de um controlo em malha fechada

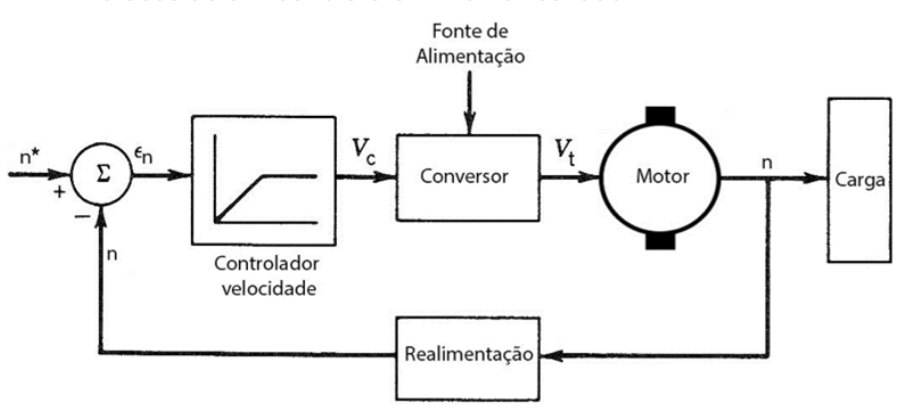

Figura 8. Controlo em malha fechada

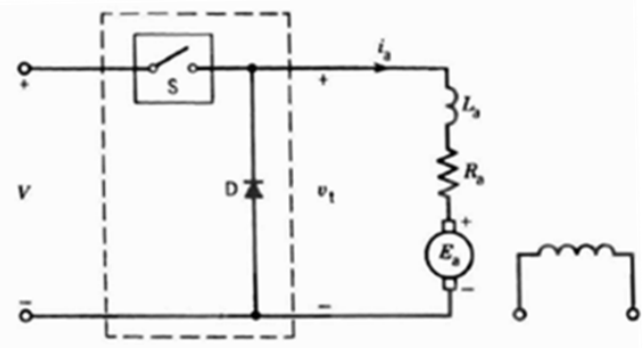

As principais vantagens da operação em malha fachada é a possibilidade de obter velocidade de funcionamento constante, a precisão no valor da velocidade obtida, excelente resposta dinâmica e estabilidade de funcionamento. 
Em malha fechada o sistema também pode ser dimensionado para funcionar a potência constante ou binário constante, ou seja, permitir uma regulação mista. Um sistema de controlo em malha fechada com anel de realimentação de corrente permite a regulação mista do motor DC. Na Figura 9 apresenta-se um diagrama de blocos dum sistema de controlo deste tipo.

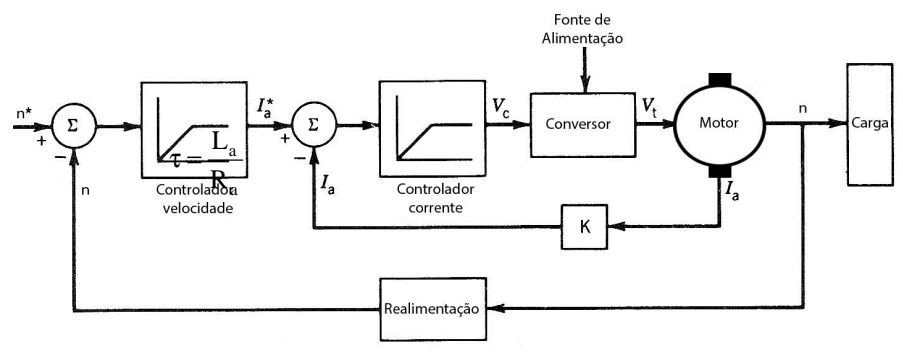

Figura 9. Controlo em malha fechada com realimentação de corrente

No motor DC, a resistência da armadura ( $\mathbf{R a}$ ) e a indutância

(La) tomam valores reduzidos. Como tal, a constante de tempo do circuito da armadura também é reduzida.

Assim, uma pequena variação da tensão aplicada resulta numa variação elevada de corrente no circuito da armadura. $\mathrm{O}$ anel de realimentação de corrente protege o conversor e o motor para variações que possam tomar valores elevados de corrente.

A saída do controlador de velocidade representa um comando de binário. Como o binário será proporcional à corrente la*, a saída do controlador de velocidade representa o controlo da corrente la. O controlador de corrente vai limitar a corrente na armadura. O controlador de velocidade e o controlador de corrente podem ser do tipo Proporcional (tipo P) ou Proporcional-Integral (tipo PI). A escolha depende da qualidade e do rigor que se pretende para o controlo em malha fechada do motor.

\section{Conclusão}

Os motores de corrente contínua são ainda muito utilizados em sistemas que requerem variação de velocidade. O controlo e a regulação de velocidade acima e abaixo da respetiva velocidade nominal é facilmente conseguido, sendo os reguladores de velocidade destas máquinas mais simples e menos dispendiosos que os reguladores de velocidade usados nas máquinas de corrente alternada.

A utilização de VEVs na regulação da velocidade de rotação dos motores de corrente contínua proporcionam uma melhoria das condições de funcionamento dos processos, um menor desgaste dos componentes mecânicos, um menor ruído de funcionamento e, fundamentalmente, uma substancial poupança de energia elétrica.

A regulação de velocidade destes motores assenta fundamentalmente no controlo e regulação da tensão aplicada na armadura e, ou, controlo da corrente de excitação do motor. Para tal, utilizam-se conversores eletrónicos baseados em retificadores controlados e choppers.

A operação destes conversores em malha fachada permite obter nos motores velocidade de funcionamento constante, maior precisão no valor da velocidade obtida, excelente resposta dinâmica e regimes de funcionamento com elevada estabilidade

\section{Bibliografia}

[1] Beleza Carvalho, J. A., Máquinas Elétricas de Corrente Contínua. Apontamentos da disciplina de Máquinas Elétricas I. ISEP, Porto, março de 2014.

[2] WEG, Motores de Corrente Contínua. www.weg.net. Catálogo WEG 2012.

[3] Sen, P.C., Principles of Electric Machines and Power Electronics. Editor: John Wiley \& Sons.

[4] Fitgerald, A.E., Charles Kingsley. Electric Machinery. Editor: McGraw Hill.

[5] ABB, Low Voltage Industrial Performance Motors. Catálogo ABB 2009. 